\title{
Experiences of family physicians after a CME ultrasound course
}

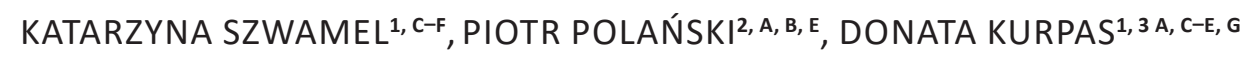

${ }^{1}$ Opole Medical School

${ }^{2}$ Family physician's practice, Non-Public Healthcare Center, Mieroszow

${ }^{3}$ Family Medicine Department, Wroclaw Medical University

A - Study Design, B - Data Collection, C - Statistical Analysis, D - Data Interpretation, E - Manuscript Preparation, F - Literature Search, G - Funds Collection

Summary Background. Ultrasonography is an inexpensive, safe, noninvasive tool for obtaining diagnoses without performing further imaging tests, and for the timely referral of patients to further diagnosis or specialist care.

Objectives. To determine which ultrasound tests are most often performed by family physicians, and what factors contribute to their use of ultrasound imaging.

Material and methods. This survey-based study using the authors' questionnaire was conducted in March 2016 among 81 primary care physicians who had completed weekend courses on ultrasound abdominal cavity imaging.

Results. Family physicians most often took ultrasounds of the abdominal cavity $(35 / 50 ; 70 \%)$ and thyroid gland $(35 / 50,12 \%)$. The odds of an ultrasound being performed at primary care centers with at least two physicians with the necessary skills were about 29.29 times higher than at centers with less than two skilled physicians (OR 29.29, 95\% CI 3.77, 1347.92). Family physicians $(46 / 81 ; 56.79 \%)$ referred 274 patients for further specialist diagnosis. The diagnosis of neoplastic disease was confirmed in 168 cases $(168 / 274 ; 61.31 \%)$. The anomalies that were most often detected by family physicians using ultrasound imaging included: cholelithiasis $(24 / 50 ; 48 \%)$, renal cysts $(16 / 50 ; 32 \%)$, nephrolithiasis $(5 / 50 ; 10 \%)$, aortic aneurysms $(2 / 50 ; 4 \%)$.

Conclusions. Family physicians' ability to perform ultrasound scans increases the probability of other doctors acquiring this skill. Weekend courses for family physicians significantly shorten patients' waiting time for such examinations. A network of professional and upto-date workshops improving the practical skills of family physicians in ultrasound diagnostics, as well as peer review groups focused on ultrasound diagnostics performed by family physicians, are recommended.

Key words: Primary health care, ultrasonography, physicians, family.

Szwamel K, Polański P, Kurpas D. Experiences of family physicians after a CME ultrasound course. Fam Med Prim Care Rev 2017; 19(1): 62-69, doi: 10.5114/fmpcr.2017.66666.

\section{Background}

The provision of high quality medical services to improve the quality of patients' lives should be counted among the priorities for primary health care centers [1]. Ultrasound examinations performed at the primary care level may increase patients' access to primary diagnostic testing. Ultrasonography is a relatively inexpensive, safe, and noninvasive diagnostic tool [2], and its use of dynamic spatial imaging [3] often allows for a diagnosis to be made without the need to perform further imaging tests [4]. As the 'new stethoscope' of a family physician, the ultrasound scanner [5] increasingly contributes to the faster onset of therapy [6] and quicker referral of patients to further diagnosis or specialist care [7].

Family physicians use ultrasound scanning to evaluate abnormalities in various superficial and deep organs of the body. Common indications for an ultrasound include chronic abdominal pain, palpable masses, flank pain, hematuria, scrotal swelling, and irregular menstrual cycles [2]. Ultrasonography has been used for 'thyroid' scans (Scotland and Spain), 'subcutaneous tissues' (Denmark, Norway), 'breasts', 'small parts', 'eyes', 'sinusitis', 'nerves', and 'ENT' [8]. Ultrasonography is a fundamental imaging technique used in patients in whom liver, gallbladder, and bile ducts diseases are suspected [4]. Ultrasound examination constitutes a basic diagnostic tool in determining the causes of obstructive jaundice, as well as in the diagnosis of liver cirrhosis and portal hypertension [9]. Mazurczak-Pluta et al. [10] underlined that carpal tunnel syndrome may be preliminarily diagnosed by family doctors using an algorithm, and the development of high-resolution ultrasound offers the chance for a quick diagnosis of the disease. Moreover, researchers in France have developed a multidisciplinary recommendation involving ultrasound specifically for the management of urolithiasis patients in primary care [11]. Bornemann et al. [12] demonstrate that point-of-care ultrasound measurement of the left ventricular mass by a primary care physician is feasible.

Ongoing innovations in technology continue to make ultrasound devices smaller and less expensive [13]. With portable ultrasound scanners at their disposal, family physicians can perform ultrasound imaging in patients who may have difficulties with access to imaging diagnosis - for example, elderly patients, those with immune deficiency, and people living in remote regions $[5,14]$.

The fact that family physicians can obtain the overall picture of a disease through their knowledge of their patients, their disease histories, clinical symptoms, and the results of additional tests (including an ultrasound) $[5,6,15]$ should be a fundamental argument for the popularization of ultrasound diagnosis in family physician's practices, as well as improving the methods and forms for educating this group of physicians to perform ultrasounds properly. Evangelista et al. [16] have claimed that handheld ultrasound performed at the point of care by family doctors, with remote expert support interpretation using a web-based system, is feasible, rapid, and useful for detect- 
ing significant echocardiographic abnormalities and decreasing the number of unnecessary echocardiographic tests. A good knowledge of ultrasound scanning techniques among family physicians could help cut the cost of medical care, since family physicians' ability to interpret the results correctly would most probably reduce the number of improper referrals to specialists [3]. For example, Fuentes Camps et al. [17] examined the cost effectiveness of the application of diagnostic algorithms to patients with first episodes of suspected deep vein thrombosis in primary care, compared to systematic referral to specialist centers. They demonstrated that: (1) one third of all referrals to hospital emergency rooms could have been avoided, and that (2) the diagnostic cost could have been reduced by $€ 8,620$ according to Oudega and $€ 9,741$ according to Wells, per 100 patients visited.

There are still too few articles in the literature describing the use of ultrasound imaging in the practices of family physicians, and especially the factors significantly contributing to the use of ultrasound scans by family physicians, the accuracy of their ultrasound-based diagnoses, and the most frequently detected pathologies of internal organs.

\section{Objectives}

The purpose of this study was to determine which ultrasound scans are most often performed in the practices of family physicians, as well as what factors determine whether ultrasound scans are performed. Additionally, we wanted to establish the advantages that result from ultrasound scanning for the most common disorders, and to specify the number of patients with suspected neoplastic lesions who are referred by family physicians for specialist consultations. Moreover, we attempted to answer the following questions: What was the trend in the number of ultrasound scans performed in practice in 2012-2015? Has completion of the ultrasound course by the family physicians significantly contributed to the shortening of the time patients waited for this examination at the primary care center? Why do some family physicians not perform ultrasound scans themselves?

\section{Material and methods}

The study was conducted in March 2016 among 81 primary health physicians who had completed a weekend course entitled "Ultrasound imaging in family medicine: the Lower-Silesian school" organized by the Innovative Medicine Cluster, Wroclaw in 2014-2016. The research was performed in line with the Declaration of Helsinki and was approved by the Bioethical Commission of the Medical University in Wroclaw (approval no. KB$-422 / 2014)$.

\section{Participants}

Our study involved 81 subjects, including 52 women (65\%) and 28 men (35\%) (1: no data), with a median age of 51 years (min-max: 28-70 years) and 18 years worked (min-max: 1-47 years). The majority of participants had completed specialist courses in family medicine $(59 / 67 ; 88.06 \%)$. Others had specialties in internal medicine $(26 / 67 ; 33.81 \%)$, pediatrics $(17 / 67 ; 25.37 \%)$, and other branches of medical practice $(8 / 67$; $11.94 \%)$. Some of the respondents $(17 / 67 ; 24.64 \%)$ were in middle of a second specialist course in family medicine, palliative care, pediatrics, or general surgery. The respondents were mainly employed in urban primary care centers $(41 / 80 ; 51.25 \%)$ and in those providing services for residents of both cities and rural areas (23/80; 28.75\%). Only 16 respondents (20\%) worked in a family physician's practice in purely rural areas. The median for the size of the population under the care of the family phy- sician's practice was 3075 people (min-max: 1235-9999). The majority of family physicians worked in a team (64/81; 79.01\%). The median for the number of physicians employed at the family physician's practice was four (min-max: 2-10), and the median number able to perform an ultrasound was two (min-max: 0-7). The participants in the course were mostly the owners of the practice they worked in $(36 / 64 ; 56.25 \%)$, but there were also employees without their own lists of patients (12/64; $18.75 \%)$, resident physicians $(12 / 64 ; 18.75 \%)$, and contract workers $(4 / 64 ; 6.25 \%)$.

\section{Description of the ultrasound course}

In Poland, radiologists perform the majority of ultrasound diagnostics that are advised by family physicians. The ultrasound course was designed for primary care physicians with many years of experience running their practices who were interested in acquiring the practical skills needed to perform ultrasound imaging upon completing the course. It was intended as a weekend workshop with instruction given by an experienced radiologist, and training with ultrasound scanners in groups of two under the watchful eye of an assistant. The course's priority was to give the participants practical training and to teach them the methodology and techniques of ultrasound imaging. The first day consisted of six and a half hours of 45-minute lectures and three and a half hours of 45 -minute practical training, with the participants examining each other. On the second day, the participants examined some patients who had been invited (four groups of six patients each over 90 minutes) and who had previously been ultrasonographically diagnosed, described, and selected. Each of the participants examined 30 people altogether. For the following two weeks, the physicians were provided with ultrasound scanners for use in their own practices. After a month, there were recapitulation meetings in which the participants were asked to describe the results of at least three of the most interesting cases they met in the forms of scans and films with descriptions. The joint analysis of the material, combined with comments from the facilitator, a summing-up seminar, and a test of the knowledge acquired constituted the final stage of the course.

\section{Study questionnaire}

Our study employed a diagnostic survey-based method using an online questionnaire of our devising, which was completed by the physicians following the course. The questionnaire consisted of 77 questions; in the current paper, 53 of the questions were analyzed. Apart from demographic data, we did include queries on the number of ultrasound scans performed, how long patients waited for this examination before and after the course, the cost of ultrasound imaging when performed for the primary care center by external providers, the most common problems faced during ultrasound examination, and the limitations and burden on the practice associated with performing ultrasound scanning. The questionnaire served also to collect data on the number of patients with suspected neoplastic lesions who were referred by their family physicians for further diagnosis, disorders detected by means of an ultrasound performed by family physicians, the interest of family physicians in prophylactic ultrasound scanning of their populations (e.g., ultrasound of the abdominal cavity organs), as well as the advantages and disadvantages of doing an ultrasound in the primary care centers, in the opinions of family physicians.

In the survey, answers for the questions about prices ultrasound of the abdomen and thyroid were expressed in zloty at first. At the stage of translating the text, zloty was converted into euro at the average exchange rate of the Polish National Bank dated 23.12.2016 year ( 1 euro $=4.4126$ zloty). The method of competent judges was applied: as a part of the pilot study, the questionnaire was completed by five family physicians; at this stage, ambiguous and doubled questions were corrected. 


\begin{tabular}{|l|l|l|l|l|l|l|l|l|}
\hline \multicolumn{2}{|l|}{ Table 1. Patients' waiting time for ultrasound scanning before and after the course, expressed as the number of working days } \\
\hline Variable & $n$ & $\begin{array}{l}\text { Means } \\
\text { course }\end{array}$ & $\begin{array}{l}\text { after the } \\
\text { course }\end{array}$ & median & $\mathrm{Cl}_{1}$ & $\mathrm{Cl}_{2}$ & $\boldsymbol{p}$ \\
\hline $\begin{array}{l}\text { Patients' waiting time for ultrasound } \\
\text { scanning as number of working days }\end{array}$ & 46 & 20.96 & 4.40 & 8.50 & 6.99 & 10.50 & $<0.001$ \\
\hline
\end{tabular}

$\mathrm{Cl}_{1}$ and $\mathrm{Cl}_{2}-95 \%$ confidence interval for (pseudo) median; $p-p$-value of the Wilcoxon signed - rank test.

Prior to the study, each participant was informed of its purpose and the expected benefits. Although they gave only the numbers of their National Health Fund contracts and no personal data, the respondents were guaranteed anonymity and the freedom to take part and withdraw at any stage. The criteria of inclusion to the study were: being a family physician and having completed the weekend course entitled "Ultrasound imaging in family medicine: the Lower-Silesian school". The return of the completed questionnaire online was considered taken as an expression of consent of the respondent to take part in the study.

\section{Statistical analysis}

In the study, all quantitative variables but three (the price of an ultrasound of the thyroid gland for the family physician's practice, the lowest acceptable price of ultrasound scanning when performed as a part of screening tests in the population under the care of the family physician's practice, and the time (expressed as the average number of working days) patients waited for an ultrasound in those family physician's practices not performing ultrasound scans) lacked normal distribution, which was verified with the Shapiro-Wilk test for the level of significance set at $p<0.05$. Spearman's rank correlation coefficient was used to calculate the strength of the correlation between the independent variables and the carrying out of ultrasound scans, the number of ultrasound scans performed in the family physician's practice, the number of patients referred to other doctors to verify the test results, and the number of accurate ultrasound-based diagnoses. Logistic regression analysis was employed to evaluate the probability of: physicians performing an ultrasound in the family physician's practice, performing ultrasound scans at a frequency higher than or equal to the median $(x \geq 5)$ each week in the family physician's practice, accurate ultrasound-based diagnoses made by the respondents, and referring patients to other doctors to verify the ultrasound results. A 95\% confidence interval was assumed for the odds ratio (OR).

The Wilcoxon signed - rank test was used to verify the hypothesis that the time patients waited for an ultrasound scan following the completion of the course by a family physician significantly diminished. The null hypothesis - that the median of differences was equal to 0 for the level of significance set at $p<0.001$ - was rejected.

The trend in the frequency of ultrasound scanning in a family physician's practice over the six-month periods from 2012 to 2015 was analyzed using two variants of the chi-square test: one verified the null hypothesis that there is no such trend, and the second verified the null hypothesis that the trend is linear (the level of significance was set at $p<0.001$ ).

R 3.1.3 (for Mac OS X 10.11.5) statistical software was used for all analysis. The critical level of significance was set as 0.05 .

\section{Results}

\section{Availability of ultrasound imaging}

The majority of family physicians (56/72; 77.78\%) stated they had ultrasound scanners in their family practice, in most cases purchased following the course, and performed ultrasound scanning $(53 / 74 ; 71.62 \%)$, mainly of the abdominal cavity $(35 / 50 ; 70 \%)$, then thyroid gland $(35 / 50,12 \%)$ and other organs $(9 / 50 ; 18 \%)$.
Approximately half of the physicians (23/50; 46.0\%) maintained that, prior to performing ultrasound scans in their practices, their patients needed to travel to other towns for ultrasound imaging. The median waiting time for an ultrasound scan at the other centers was 14 days (min-max: 0-180 days), the median distance between these locations and the family physician's practices was $7 \mathrm{~km}$ (min-max: 0-45 km), and the median price for an ultrasound of the abdominal cavity paid by the practice was $11.33 €$ (min-max: 4.53-18.13 $€$ ). The mean price for an ultrasound of the thyroid gland was $11.16 € \pm 4.12 €$.

Patients' waiting time for ultrasound scanning following the completion of the course by the physicians significantly shortened. The average waiting time before and after the course (expressed as the number of working days) was 20.96 and 4.40 respectively (Table 1 ).

\section{Determinants of doing ultrasound imaging in the family physician's practice}

Every second physician taking part in the study asserted that he or she sometimes performed an ultrasound during visits $(42 / 50 ; 84 \%)$. The median number of ultrasound scans performed by family physicians in a week during one visit was two (min-max: 1-10). Family physicians indicated they have performed about five ultrasound scans per week (min-max: 1-25) since they have become capable of performing ultrasound imaging.

The fact that a physician was performing ultrasound scanning correlated positively with the number of physicians able to perform this examination at the center $(r=0.59, p<0.001)$ (Table 2). The odds that a physician carried out an ultrasound scan in a primary care center where at least two physicians had the skills necessary to perform ultrasound examination were about 29.29 times higher than in centers where the number of doctors with such skills was lower than two: OR $29.29,95 \% \mathrm{Cl} 3.77-$ -1347.92 . The proportions of physicians performing ultrasounds at both types of primary care centers were $96.4 \%$ and $46.4 \%$ respectively $(p<0.001)$. There were no significant relationships between the fact of performing an ultrasound and such variables as the age of the family physicians, years worked, the size of the population under the care of the primary care center, the total number of physicians employed in the center, the distance between the primary care center and other center providing ultrasound services, the waiting time for this examination at another center, the price of an ultrasound at another center, or the number of ultrasound scans performed independently.

The number of ultrasound scans performed per week by family physicians correlated negatively with the number of physicians able to perform this examination in the family physician's practice $(r=-0.37, p=0.029)$ (Table 2$)$. An increase in the number of physicians skilled in the use of ultrasound scanners corresponded with a smaller number of ultrasound scans done per week. However, the odds that at least five ultrasound scans would be performed in primary care centers where at least two physicians were trained to perform this examination were the same as in other primary care centers. The OR was 0.27 and its $95 \% \mathrm{Cl}: 0.04-1.54$. The proportions of physicians performing at least five ultrasound scans in both types of a primary care center were $40 \%$ and $72 \%$, respectively, and did not significantly differ $(p=0.123)$. 
Table 2. The values of Spearman's rank correlation coefficient between quantitative variables and the fact of providing ultrasound services (PUS), the number of ultrasound scans performed in the family physician's practice (NUS), the number of patients referred to other doctors to verify the test results (NP)

\begin{tabular}{|c|c|c|c|c|c|c|c|c|c|}
\hline \multirow[t]{2}{*}{ Variable } & \multicolumn{3}{|c|}{$\begin{array}{l}\text { PUS } \\
\text { no (1), yes (2) }\end{array}$} & \multicolumn{3}{|c|}{ NUS } & \multicolumn{3}{|l|}{ NP } \\
\hline & $n_{1}$ & $r_{1}$ & $p_{1}$ & $n_{2}$ & $r_{2}$ & $p_{2}$ & $n_{3}$ & $r_{3}$ & $p_{3}$ \\
\hline Age (years) & 73 & -0.10 & 0.386 & 47 & 0.11 & 0.479 & 30 & -0.31 & 0.091 \\
\hline Years worked & 73 & -0.14 & 0.222 & 47 & 0.10 & 0.524 & 30 & -0.41 & 0.026 \\
\hline $\begin{array}{l}\text { Size of the population under the care of } \\
\text { the family physician's practice }\end{array}$ & 63 & 0.01 & 0.957 & 42 & 0.00 & 0.991 & 27 & 0.10 & 0.643 \\
\hline Total number of physicians in the practice & 54 & -0.04 & 0.794 & 34 & -0.40 & 0.020 & 22 & -0.05 & 0.830 \\
\hline $\begin{array}{l}\text { The number of primary health physicians } \\
\text { able to perform ultrasound in the family } \\
\text { physician's practice }\end{array}$ & 56 & 0.59 & 0 & 35 & -0.37 & 0.029 & 23 & -0.11 & 0.605 \\
\hline $\begin{array}{l}\text { The number of kilometers from the family } \\
\text { physician's practice to the nearest medi- } \\
\text { cal center providing ultrasound services }\end{array}$ & 49 & - & - & 46 & 0.08 & 0.586 & 29 & 0.14 & 0.476 \\
\hline $\begin{array}{l}\text { Waiting time for ultrasound in another } \\
\text { medical center }\end{array}$ & 46 & - & - & 44 & 0.01 & 0.928 & 29 & -0.04 & 0.820 \\
\hline $\begin{array}{l}\text { Cost of abdominal cavity ultrasound in } \\
\text { another medical center }\end{array}$ & 41 & - & - & 40 & -0.22 & 0.184 & 26 & -0.05 & 0.830 \\
\hline $\begin{array}{l}\text { Cost of thyroid ultrasound in another } \\
\text { medical center }\end{array}$ & 37 & - & - & 36 & -0.20 & 0.261 & 23 & 0.05 & 0.817 \\
\hline $\begin{array}{l}\text { Number of ultrasound scans performed } \\
\text { in the family physician's practice }\end{array}$ & 47 & - & - & - & - & - & 29 & 0.35 & 0.060 \\
\hline
\end{tabular}

$n_{\mathrm{i}}$ - number of observations; $r_{\mathrm{i}}$ - Spearman's rank correlation coefficient; $p_{\mathrm{i}}$ - the level of significance calculated for the null hypothesis that $r_{\mathrm{i}}=0$ ( 0 denotes $p<0.001$ ). PUS - the fact of providing ultrasound services; NUS - the number of ultrasound scans performed in the family physician's practice; NP - the number of patients referred to other doctors to verify the test results.

Table 3. Distribution of the frequency of ultrasound tests in the six-month periods of 2012-2015

\begin{tabular}{|c|c|c|c|c|c|c|c|c|c|}
\hline Ultrasound & & 2012.06 & 2012.12 & 2013.06 & 2013.12 & 2014.06 & 2014.12 & 2015.06 & 2015.12 \\
\hline yes & $n$ & 3535 & 3375 & 3712 & 3868 & 3930 & 3822 & 4610 & 4153 \\
\hline no & $n$ & 132482 & 132642 & 132305 & 132149 & 132087 & 132195 & 131407 & 115553 \\
\hline Total & $n$ & 136017 & 136017 & 136017 & 136017 & 136017 & 136017 & 136017 & 119706 \\
\hline yes & $\%$ & 2.6 & 2.5 & 2.7 & 2.8 & 2.9 & 2.8 & 3.4 & 3.5 \\
\hline no & $\%$ & 97.4 & 97.5 & 97.3 & 97.2 & 97.1 & 97.2 & 96.6 & 96.5 \\
\hline \multicolumn{2}{|l|}{ Null hypothesis } & \multicolumn{2}{|c|}{ chi-square } & $d f$ & $p$ & & & & \\
\hline \multicolumn{2}{|l|}{ no trend } & \multicolumn{2}{|l|}{325.51} & 1 & $<0.001$ & & & & \\
\hline \multicolumn{2}{|l|}{ linear trend } & \multicolumn{2}{|l|}{76.77} & 6 & $<0.001$ & & & & \\
\hline
\end{tabular}

The number of ultrasound scans performed per week correlated significantly only with the type of family physician's practice $(r=0.34, p=0.021$ ) (Table 2$)$. However, Fisher's test for independence for the distribution of the number of ultrasound scans divided into two groups (above and below the median; $x<5$ and $x \geq 5$ ) performed in particular types of the family physician's practice did not confirm this relationship $(p=0.397)$.

A higher number of all physicians in the practice correlated with a lower number of ultrasound scans performed there per week ( $r=-0.40, p=0.020$ ) (Table 2). Nonetheless, the odds of at least five ultrasound scans being performed in primary care centers employing no more four physicians were the same as in other centers: OR $0.72,95 \% \mathrm{Cl} 0.12-3.26$. The proportions of physicians performing at least five ultrasound scans at both types of primary care centers were $31.6 \%$ and $42.9 \%$, respectively, and did not significantly differ $(p=0.716)$.

A significant time trend for the number of ultrasound scans performed in primary care centers was observed from June 2012 to December 2015 ( $p<0.001$ ). The percentage of ultrasound scans performed by family physicians increased with time. However, this not a linear trend $(p<0.001)$; there were small but significant deviations from the linear relationship with time (Table 3).

\section{Referrals to radiologists}

Only a small proportion of family physicians $(3 / 51 ; 5.88 \%)$ did not refer their patients to a radiologist to verify the ultrasound results that they obtained over the last six months. The median number of patients referred to a radiologist by one physician in this period was seven (min-max: 0-100). The number of patients referred to other doctors to verify the ultrasound results correlated negatively with years worked $(r=-0.41, p=$ 0.026). Experienced physicians less frequently referred their patients to other doctors to verify ultrasound results. However, the odds that a physician referred no more than six patients to another doctor to verify ultrasound results over six months were the same in the group of physicians with less than 18 years worked and all other physicians (OR $0.35,95 \% \mathrm{Cl}$ : 0.06-1.84). The number of physicians referring no more than six patients in 
both years-worked grouping was $64.3 \%$ and $37.5 \%$, respectively, and did not significantly differ $(p=0.273)$. There was also no significant connection between the number of patients referred to another doctor to verify ultrasound results and variables such as the age of the respondents, the number of ultrasound scans performed, the system of work, or the specialty.

Over the last six months, the family physicians included in this study $(46 / 81 ; 56.79 \%)$ referred a total number of 274 patients for further specialist diagnosis, including 154 so-called symptomatic patients with suspected neoplastic lesions (tumors) $(154 / 274 ; 56.2 \%)$ and 120 nonsymptomatic patients who had accidentally been detected (120/274; 43.8\%). The diagnosis of neoplastic disease was confirmed in 168 cases (168/274; $61.31 \%)$. The median number of so-called symptomatic patients over six months for each of the physicians in the study was two (min-max: 0-16), and the number of nonsymptomatic patients was 1 (min-max: 0-16). The median number of cases in which a suspected neoplastic disease was confirmed per family physician was 2 (min-max: 0-30). Provision of ultrasound services in the family physician's practice required physicians to adjust their work schedule $(33 / 49 ; 67.35 \%)$ or to start work earlier $(14 / 49 ; 28.75 \%)$. The main part of those surveyed did not perceive the provision of ultrasound services as a great burden for work organization in the primary care center (41/49; 83.67\%). The median time spent by respondents on ultrasound scanning per week was three hours (min-max: 1-12).

\section{Compatibility of diagnoses between family physicians and radiologists}

The number of ultrasound diagnoses compatible with radiologists within the group of patients refer to radiologists correlated significantly negatively with the number of family physicians providing ultrasound services in the practice $(r=-0.38$, $p=0.040$ ) and positively with both the number of ultrasound examinations performed in the center $(r=0.55, p=<0.001)$ and with sex $(r=0.45, p=0.002)$.

Men more often made compatible ultrasound diagnoses (OR 8.32, 95\% Cl: 1.47-89.73). The number of physicians with at least two compatible diagnoses in the male and female groups were $87.5 \%$ and $44.4 \%$, respectively, and significantly differed $(p=0.009)$.

The number of ultrasound diagnoses compatible with radiologists correlated positively also with the type of primary care center $(r=0.37, p=0.014)$ : compatible diagnoses were most often made in centers that provided services for both urban and rural areas, and most seldom in rural primary care centers. The highest frequency (86.7\%) of at least two compatible diagnoses was seen in centers providing for both urban and rural centers, and the lower (41.2\%) in urban centers.

\section{Most commonly detected pathologies in primary care centers}

The anomalies that were most often detected by family physicians using ultrasound imaging included: cholelithiasis (24/50; $48 \%)$, renal cysts $(16 / 50 ; 32 \%)$, nephrolithiasis $(5 / 50 ; 10 \%)$, aortic aneurysms $(2 / 50 ; 4 \%)$, hepatic cysts $(2 / 50 ; 4 \%)$ and prostatic hypertrophy $(1 / 50 ; 2 \%)$. Ultrasound scans being performed in the practice allowed for the following disorders to be detected: aortic aneurysms, renal cancer, hydronephrosis, primary hepatic carcinoma, hepatic aneurysms, cancer of the pancreatic body, polycystic kidney disease, renal agenesis, myomata uteri, autoimmunological hepatitis, adrenal gland tumor, gallbladder carcinoma, liver metastases, spleen angioma, renal cirrhosis, gallbladder hydrops, urinary bladder papilloma, appendicitis, gallbladder polyps, hepatic steatosis, complex renal cyst, angiomyolipoma, diverticulitis, renal hypoplasia, bladder recess, suppurated cyst of the pancreas, large thrombus parietalis in the aorta, large polycystic ovarian lesion, colon tumor, ovarian tumor, cancer of the testis, prostate cancer, horseshoe kidney, confirmed duplication of the pelvicalyceal system, cancer of the urinary bladder, thyroid tumors, Hashimoto's disease, Graves' disease, post-traumatic lesions in the knee joint, and meniscus injuries.

\section{Advantages of ultrasound examinations}

$50.6 \%$ of family physicians $(41 / 81)$ believed that the only indication for ultrasound scanning is the fact that the patient has never had it before. Ultrasound scanning helps improve skills $(33 / 39 ; 84.62 \%)$, was regarded as favorable to patients because of the possibility of screening the population (29/39; $74.36 \%)$, and made it possible to comply with patients' requests (19/39; $48.72 \%$ ). Some $70.59 \%$ (36/51) of the surveyed asserted that they would be interested in screening their populations (e.g., over five years) if they were additionally paid for this. The average lowest acceptable price for one ultrasound was $8.75 € \pm 3.49 €$.

What was most important for family physicians was the fact that their ability to perform ultrasound resulted, in their opinion, in greater recognition from patients (21/49; $42.86 \%)$, higher confidence in the primary care center $(21 / 49 ; 42.86 \%)$, and recognition from other specialists, especially when their diagnoses proved accurate $(9 / 48 ; 18.75 \%)$; however family physicians $(5 / 48 ; 10.42 \%)$ thought that other specialists might have doubts about their skills.

The most important reason for not performing ultrasound given by physicians was the need to improve their skills in performing this examination on their own $(6 / 16 ; 37.5 \%)$; other reasons were also given $(6 / 16 ; 37.5 \%)$. Nine of the family physicians would consider performing ultrasound scans on their own in under the condition that they had their own ultrasound scanners; seven physicians indicated that they would begin performing ultrasounds following the completion of other courses. These physicians usually sent patient for ultrasound scans to other doctors in their medical centers $(9 / 18 ; 50 \%)$, in the same town $(7 / 18 ; 38.89 \%)$, or in another town $(2 / 18 ; 11.11 \%)$. The median distance between the other locations and the primary care center was $0.5 \mathrm{~km}$ (min-max: $0-15 \mathrm{~km})$. The average waiting time for ultrasound in these centers was seven working days \pm 3 days. The median price paid by the center was $9.06 €$ (min-max; 6.80-13.60 €) for an ultrasound scan of the abdominal cavity and also $9.06 €$ (min-max: 5.67-13.60 €) for an ultrasound scan of the thyroid gland.

The majority of family physicians believed that ultrasound imaging in family medicine improves the detectability of many diseases (59/66; 89.39\%). The fundamental advantage is that the ultrasound is performed by a doctor who knows the medical history of the patient $(51 / 66 ; 77.27 \%)$, and binary assessment of the pathology makes further management of the patient much easier (36/66; 54.55\%).

The most important reported advantages of being skilled in using ultrasound scanners included quicker diagnosis of patients $(26 / 62 ; 41.94 \%)$, the possibility of expanding knowledge $(20 / 62 ; 32.26 \%)$, fulfillment of a longstanding desire to performing ultrasound scanning $(6 / 62 ; 9.68 \%)$, fighting against burnt out $(4 / 62 ; 6.45 \%)$, extending the array of services $(2 / 62 ; 3.23 \%)$, other reasons $(2 / 62 ; 3.23 \%)$, gaining prestige in the eyes of patients and staff $(1 / 62 ; 1.61 \%)$, and a new passion (1/62; $1.61 \%)$. Most respondents held the opinion that ultrasound scanning should be one of services provided in a primary care center (36/53; 67.92\%). Only a small percentage of family physicians were skeptical of providing ultrasound services, and ticked the following answers: "we'll never be radiologists" (6/53; 11.32\%), "we cannot be experts at everything" (5/53; 9.43\%), "we don't have the appropriate qualification from a professional society" $(1 / 53 ; 1.89 \%)$, "performing ultrasounds is financially unprofitable" $(1 / 53 ; 1.89)$, and "performing ultrasounds is too timeconsuming" (1/53; $1.89 \%)$. A small group of respondents $(3 / 53$; $5.66 \%)$ indicated that their skepticism is caused by another reason. 


\section{Discussion}

\section{Ultrasound in the family physician's practice: prospects for the future}

The use of ultrasound by nonradiologists has outpaced radiologist performed ultrasound in the last decade [18]. Our survey also confirms this statement, showing a significant upward nonlinear trend in the period 2012-2015 of the number of ultrasound scans performed in the primary care centers examined. Smith-Bindman et al. [19] have suggested that the factors contributing to the rise in the volume of imaging services include greater availability and accessibility, increased demand by patients and physicians, favorable reimbursement, and improvement in the quality of imaging techniques.

The only noteworthy determinant of whether a physician performs ultrasound scanning that results from our analysis is the number of physicians who perform this examination in the center. Though this relationship seems to be obvious, it does not have to be so: a greater number of physicians who perform ultrasound in a particular center does not necessarily imply that the percentage of the physicians performing ultrasound in this center is higher than in another center with fewer such physicians (it may be the case that there are fewer physicians in the second center).

\section{Most-frequently performed ultrasound scans}

The family physicians in our study most often performed ultrasound scans of the abdominal cavity and thyroid gland. Alamri et al. [2] described the frequency in primary care of ultrasound scans of different types as follows: abdomen/pelvis $(60 \%)$, breasts $(13 \%)$, kidneys, ureters, and bladder (11\%), thyroid $(8 \%)$, scrotum $(7 \%)$, and hips (1\%). Bujnowska-Fedak and Krawiecka-Jaworska [20] have mentioned that abdominal pain is the most common problem in general practice. These researchers also state that ultrasonography of abdominal cavity has become the first and a very useful imaging technique in patients with nonspecific abdominal pain. In Austria, Finland, Greenland, Iceland, and Norway, family physicians perform FAST (Focused Abdominal Sonography Trauma) examinations [8]. Piskunowicz et al. [21] also confirm that the ultrasound scan that is most often performed in children and adults at a family physician's practice involves the abdominal cavity; ultrasound scans of the thyroid gland, neck (evaluating the lymph and salivary glands), hip joints, and fontanel are performed much less frequently. Acute abdominal pain accounts for approximately $9 \%$ of childhood primary care office visits. Ultrasonography is the first choice in children for the diagnosis of cholecystitis, pancreatitis, ovarian cysts, ovarian or testicular torsion, pelvic inflammatory disease, pregnancy-related pathology, and appendicitis [22]. Knop and Stauning [23] concluded that abdominal ultrasound and radiographic examination of the thoracic and lumbar spine in primary care have been performed more often than other diagnostic imaging examinations, and more frequently resulted in clinical intervention. This has demonstrated the accuracy of family doctors' diagnoses.

Mengel-Jørgensen and Jensen [8] stated that, in most countries and regions, of the 12 they surveyed, the indications for family physicians to use point-of-care ultrasound included obstetric, gynecological, urogenital, musculoskeletal/joint, abdominal, cardiac, and vascular issues. However, in Austria, Catalonia, and Switzerland ultrasound did not seem to be used for obstetric or gynecological examinations. But Kozuki et al. [24] indicated that, with limited training, primary-level health care workers can accurately diagnose selected third-trimester obstetric risk factors using ultrasonography.

Despite the reports of Scholten-Peeters et al. [25] that radiologists and orthopedic surgeons sampled in the Netherlands displayed low trust of the diagnostic musculoskeletal ultrasound knowledge of family physicians, Kumar et al. [26] have demonstrated that the use of musculoskeletal ultrasound to image inflamed joints helps to improve patient adherence to diseasemodifying antirheumatic drugs. Considering the phenomenon of patients' multimorbidity [27] and the long waiting time for outpatient specialist care [28], this argument should additionally motivate family physicians to participate in courses in musculoskeletal ultrasound and ultrasound of other parts of the body.

\section{Economic aspects of providing ultrasound services}

Our study has demonstrated that, although the provision of ultrasound services in the center requires adjustments in the work schedule or even starting work earlier, it nonetheless does not represent a great burden for the organization of work. Genc et al. [6] and Kosiak [5] claim that ultrasound scan performed by a family physician in accordance with the point-of-care principle (i.e., performing the examination and interpreting the result in the course of making a therapeutic decision, in order to confirm the suspected pathology) does not extend the time of the visit, because the time taken for the examination of, for example, the lungs is similar when performed by ultrasound and by stethoscope.

In this study, every second family physician declared that he or she would be interested in screening their populations using ultrasound (e.g., over five years), if this option was additionally funded by the National Health Fund; the average lowest acceptable price for one ultrasound scan was $8.75 \pm 3.49 €$. For comparison, the public health insurance system in Finland pays $€ 15-20$ per examination. In the Netherlands, a family physician qualified to perform ultrasound examinations earns $€ 60$ to $€ 70$ for an abdominal scan. In Germany, basic ultrasound examination costs lie between $€ 32$ and $€ 52$ [8].

\section{Pathologies and diagnostic accuracy within referred to radiologists}

Our study showed that neoplastic disease was confirmed in $61.31 \%$ of the patients $(168 / 274)$ referred for further diagnosis by the family physicians. It should be emphasized that this question was answered by less than half of the respondents ( 46 subjects); the proportion would presumably be higher if all respondents had answered the question. In another study conducted in a primary care center, pathologies of the abdominal cavity and the retroperitoneal space were detected or confirmed in 248 out of 369 patients. In 27 patients, it was not possible to make a final diagnosis on the basis of the ultrasound due to clinical symptoms, so they were referred for further gastroenterological, urological, or gynecological consultations [7].

The health problems most often diagnosed by the family physicians in our study were cholelithiasis, renal cysts, nephrolithiasis, aortic aneurysms, and hepatic cysts. Sowińska-Neuman [7] mentioned cholelithiasis, hepatic steatosis, extensive hepatic parenchymal damage, hepatic cysts, hepatic stasis, and extension to the common bile duct as examples of the digestive tract pathologies detected in primary care centers. The urinary pathologies listed by her included nephrolithiasis, renal cysts, and pelvicalyceal stasis.

The ultrasound scans performed by the family physicians in our study contributed to the detection of aortic aneurysms. Motte [29] mentioned that family physicians also could play a key role in prevention of abdominal aortic aneurysm. Ruff et al. [30] claimed that most abdominal aortic aneurysms are completely incidental; they also mentioned that abdominal ultrasounds are the preferred screening method for abdominal aortic aneurysms, because this tool has $95 \%$ sensitivity and nearly $100 \%$ specificity for detecting abdominal aortic aneurysm in asymptomatic patients.

Ultrasound also enabled the physicians in our study to detect such interesting disorders as renal cancer, hydronephrosis, primary hepatic carcinoma, hepatic angiomas, cancer of the 
pancreatic body, polycystic kidney disease, renal agenesis, myomata uteri, autoimmunological hepatitis, adrenal gland tumor, and others. Among the rarer diagnoses of abdominal cavity pathology, Sowińska-Neuman [7] listed adrenal gland tumor, abdominal aortic aneurysm, iliac aortic aneurysm, umbilical hernia, atherosclerosis of the abdominal arteries, abdominal dropsy, the presence of pleural fluid and, among the urogenital pathologies, duplication of the pelvicalyceal system, renal cancer (probably malignant), neurogenic bladder, nephrocalcinosis, and angiomyolipoma. Cwojdzińska-Jankowska and Plewa [31] emphasized the great relevance of ultrasound examination in general practice in patients with autosomal dominant polycystic kidney disease.

\section{Reasons for physicians lacking motivation to take part in courses}

We must consider why some family physicians do not perform ultrasound in their centers. This group had rather more favorable conditions for their patients to receive ultrasound services in other centers, comparing to their counterparts who are capable of performing ultrasound. These conditions included shorter median distances from the radiological centers to the family physician's practice $(0.5 \mathrm{~km}$ vs. $7 \mathrm{~km})$, shorter waiting times for ultrasound ( 7 days \pm 3 days vs. 14 days), and lower median prices for ultrasound of the thyroid gland (9.06 € vs. 11.16 $\pm 4.12 €)$ and the abdominal cavity ( $9.06 €$ vs. $11.33 €)$. We can thus assume that this group of family physicians lacks the motivation to participate in training courses. However, no significant correlation was found in our study between the fact of providing ultrasound services and variables such as the distance from the family physician's practice to another center offering ultrasound scanning, waiting time, or the price for ultrasound in another center. These relationships require further investigation.

Nevertheless, the above data, the fact that only a small proportion of family physicians did not refer their patients to a radiologist in order to verify ultrasound results, and the respondents' explanation that the main reason for not performing ultrasound is the need to improve their skills, indicate that there is a necessity for more ultrasound courses for family physicians.

\section{Limitations of the study}

The size of the study group was too small, which, however, can be partially justified by purposive sampling (physicians who have completed a weekend ultrasound course). In the future, it would be interesting to conduct a similar study of a larger study sample, including all family physicians - such as those not attending ultrasound courses - with regard to the demographic stratification of the participants (primary care centers in cities and in the country).

Finally, we did not aim to assess the accuracy of all ultrasound diagnoses performed by the surveyed family physicians. The estimation of accuracy was limited to the cluster of patients referred to radiologist.

\section{Conclusions}

The ability to perform ultrasound by family physicians in a particular primary care center notably increases the probability of their colleagues acquiring this skill. We can expect in future that the number of ultrasound scans performed in primary care centers will increase, which may potentially improve the detectability of neoplastic diseases. Preferred aspects which support the idea of continuing a training weekend in the field of ultrasound and performing ultrasound examinations by GPs are: detection rate of cancer at a level of $61.31 \%$, greater recognition from patients equal to other specialists and higher confidence in the primary care center. Considering patients' multimorbidity and the long waiting time for outpatient specialist care, it is desirable that physicians should develop their abilities to perform ultrasound. Ultrasound courses for family physicians considerably reduce the waiting time for this examination. A recommendation of the authors would be to create a network of professional and up-to-date workshops improving the practical skills of family physicians in ultrasound diagnostics, as well as peer review groups focused on ultrasound diagnostics performed by family physicians.

Acknowledgements. The authors would like to thank Dr. Ewa Nienartowicz and the family physicians involved in the research (Katarzyna Trybucka, Lucyna Polańska, Barbara Dybek, Agata Sławin, Paweł Brzozowski, Jan Duda, Zbigniew Tyszkowski, Anna Krzyszowska-Kamińska, and Piotr Stankiewicz) for their factual suggestions.

Source of funding: This work was founded by funds allocated to the statutory activities of the Department of Family Medicine Medical University in Wroclaw.

Conflict of interest: The authors declare no conflict of interests.

\section{References}

1. Kanecki K, Nitsch-Osuch A, Tyszko PZ. Health-Related Quality of Life or Quality of Medical Service? Current challenges for family doctors. Fam Med Prim Care Rev 2016; 18(3): 382-386.

2. Alamri AF, Khan I, Baig MI, et al. Trends in ultrasound examination in family practice. J Family Community Med 2014; 21(2): 107-111. doi: 10.4103/2230-8229.134767.

3. Kosiak W, Kryger M. Ultrasonografia w gabinecie lekarza rodzinnego - za i przeciw. Fam Med Prim Care Rev 2012; 14(2): 249-250.

4. Walas MK, Skoczylas K, Gierbliński I. Standards of the Polish Ultrasound Society - update. The liver, gallbladder and bile ducts examinations. J Ultrason 2012; 12(51): 428-445.

5. Kosiak W. Ultrasonograf stetoskopem lekarza rodzinnego. Fam Med Prim Care Rev 2010; 12(2): 389-393.

6. Genc A, Ryk M, Suwała M, et al. Ultrasound imaging in the general practitioner's office - a literature review. J Ultrason 2016; 16(64): 78-86, doi: 10.15557/JoU.2016.0008.

7. Sowińska-Neuman L. Umiejętność samodzielnego wykonywania badań ultrasonograficznych w praktyce lekarza rodzinnego. Ultrasonografia 2009; 9(38): 51-54.

8. Mengel-Jørgensen T, Jensen MB. Variation in the use of point-of-care ultrasound in general practice in various European countries. Results of a survey among experts. Eur J Gen Pract 2016: 1-4, doi: 10.1080/13814788.2016.1211105.

9. Hernaez R, Lazo M, Bonekamp S, et al. Diagnostic accuracy and reliability of ultrasonography for the detection of fatty liver: a meta-analysis. Hepatology 2011; 54(3): 1082-1090.

10. Mazurczak-Pluta T, Pomianowski S, Szopiński K: Zespół kanału nadgarstka w praktyce lekarza rodzinnego. Znaczenie badania ultrasonograficznego w odniesieniu do elektromiografii. Ultrasonografia 2007; 31(31): 73-84.

11. Abergel S, Peyronnet B, Seguin P, et al. Management of urinary stone disease in general practice: A French Delphi study. Eur J Gen Pract 2016; 22(2): 103-110, doi: 10.3109/13814788.2016.1149568.

12. Bornemann P, Johnson J, Tiglao S, et al. Assessment of Primary Care Physicians' use of a pocket ultrasound device to measure left ventricular mass in patients with hypertension. J Am Board Fam Med 2015; 28(6): 706-712, doi: 10.3122/jabfm.2015.06.140314. 
13. Hall JW, Holman H, Bornemann P, et al. Point of care ultrasound in family medicine residency programs: A CERA study. Fam Med 2015; 47(9): 706-711.

14. Zhao PJ. Ultrasound in the rural and remote healthcare setting. UWOMJ 2014; 83(1): 30-31.

15. Bień S. The importance of General Practitioner in diagnosis and treatment of a mass in the neck. Probl Med Rodz 2012; 3(39): 49-55.

16. Evangelista A, Galuppo V, Méndez J, et al. Hand-held cardiac ultrasound screening performed by family doctors with remote expert support interpretation. Heart 2016; 102(5): 376-382, doi: 10.1136/heartjnl-2015-308421.

17. Fuentes Camps E, Luis Del Val García J, Bellmunt Montoya S, et al. Cost-effectiveness of the deep vein thrombosis diagnosis process in primary care. Aten Primaria 2016; 48(4): 251-257, doi: 10.1016/j.aprim.2015.05.006.

18. Levin DC, Rao VM, Parker L, et al. Noncardiac point-of-care ultrasound by nonradiologist physicians: how widespread is it? J Am Coll Radiol 2011; 8(11): 772-775.

19. Smith-Bindman R, Miglioretti DL, Larson EB. Rising use of diagnostic medical imaging in a large integrated health system. Health Aff (Millwood) 2008; 27(6): 1491-1502.

20. Bujnowska-Fedak MM, Krawiecka-Jaworska E. Rola i przydatność badania ultrasonograficznego w rozpoznawaniu bólów brzucha w praktyce lekarza rodzinnego. Fam Med Prim Care Rev 2009; 11(1): 21-25.

21. Piskunowicz M, Kosiak W, Świętoń D. Nowe technologie w obrazowaniu ultrasonograficznym - ich przydatność w gabinecie ultrasonograficznym lekarza rodzinnego. Fam Med Prim Care Rev 2008; 10(3): 1014-1017.

22. Reust CE, Williams A. Acute abdominal pain in children. Am Fam Physician 2016; 93(10): 830-836.

23. Knop FK, Stauning JA. The benefits of diagnostic imaging in general practice. Ugeskr Laeger 200; 168(8): 794-798.

24. Kozuki N, Mullany LC, Khatry SK, et al. Accuracy of home-based ultrasonographic diagnosis of obstetric risk factors by primary-level health care workers in rural Nepal. Obstet Gynecol 2016; 128(3): 604-612.

25. Scholten-Peeters GG, Franken N, Beumer A, et al. The opinion and experiences of Dutch orthopedic surgeons and radiologists about diagnostic musculoskeletal ultrasound imaging in primary care: a survey. Man Ther 2014; 19(2): 109-113, doi: 10.1016/j.math.2013.08.003.

26. Kumar K, Raza K, Gill P, et al. The impact of using musculoskeletal ultrasound imaging and other influencing factors on medication adherence in patients with rheumatoid arthritis: a qualitative study. Patient Prefer Adherence 2016; 10: 1091-1100, doi: 10.2147/PPA. S99702.

27. Kurpas D. Paradygmat opieki nad chorymi przewlekle w ramach podstawowej opieki zdrowotnej. (Rozprawy Habilitacyjne Uniwersytetu Medycznego we Wrocławiu; 6/2013). Wrocław: Uniwersytet Medyczny im. Piastów Śląskich; 2013.

28. Realizacja zadań Narodowego Funduszu Zdrowia w ramach planu finansowego na 2013 rok. Raport NIK. KZD-4101-001-01/2014 Nr ewid. 165/2014/P/14/060/KZD [cited 03.04.2016]. Available from URL: https://www.nik.gov.pl/plik/id,7653,vp,9595.pdf.

29. Motte $\mathrm{S}$. What is the evidence to support screening for abdominal aortic aneurysm and what is the role of the primary care physicians? Rev Med Brux 2015; 36(4): 343-347.

30. Ruff AL, Teng K, Hu B, et al. Screening for abdominal aortic aneurysms in outpatient primary care clinics. Am J Med 2015; 128(3): 283-288, doi: 10.1016/j.amjmed.2014.10.036.

31. Cwojdzińska-Jankowska I, Plewa A. Relevance of ultrasound examination in general practice. A case report of a patient with autosomal dominant polycystic kidney disease. J Ultrason 2013; 13(54): 344-349.

Tables: 3

Figures: 0

References: 31

Received: 26.12 .2016

Revised: 14.01 .2017

Accepted: 14.01.2017

Address for correspondence:

Katarzyna Szwamel, MSc

Opole Medical School

ul. Katowicka 68

45-060 Opole

Polska

Tel.: +48 605 513-431

E-mail: k.szwamel@interia.pl 